\title{
aniki
}

Revista Portuguesa da Imagem em Movimento

Portuguese Journal of the Moving Image

\section{O mundo é um palco: a teatralidade em 'Depois do ensaio', de Ingmar Bergman \\ Gustavo Ramos de Souza}

\section{Introdução}

"O teatro é minha mulher, mas o cinema é minha amante.” Ingmar Bergman

Depois de anunciar que Fanny \& Alexander (1982) seria o seu último filme, o cineasta Ingmar Bergman realizou, em 1984, para a televisão sueca, o filme Depois do ensaio [Efter repetitionen], uma espécie de balanço autobiográfico de sua obra que, para além de suas obsessões de sempre, trata diretamente de uma de suas paixões: o teatro. Se o filme lança luz sobre toda a sua carreira, revendo ironicamente temas recorrentes de seus filmes anteriores, como o inferno conjugal, a finitude e a angústia existencial, logra também refletir sobre o significado de dicotomias como sonho/realidade e teatro/vida, que, de resto, fazem parte do universo do dramaturgo sueco August Strindberg, por quem Bergman nutria especial admiração. Aliás, se o espectro de Strindberg já atravessa os filmes anteriores do cineasta, em Depois do ensaio, a homenagem se faz explícita, na medida em que é a partir da montagem da peça O sonho [Ett Drömspel, 1902] que o filme se desenvolve.

Tendo isso em vista, este artigo propõe-se analisar o filme Depois do ensaio, com o intuito de verificar de que maneira Bergman realiza um amálgama entre cinema e teatro. Para tanto, o artigo divide-se em três partes complementares: primeiramente, a partir dos estudos de André Bazin (2014), de Béatrice Picon-Vallin (2008) e de Michèle Garneau (2010) acerca da teatralidade no cinema, bem como da classificação proposta por Irina Rajewsky (2012) a respeito das práticas intermidiáticas, visa-se delimitar a noção de teatralidade e a forma como esta se articula à linguagem cinematográfica; em seguida, com base nos estudos de Egil Törnkvist (1995, 2003, 2013), busca-se traçar aproximações entre a obra de Ingmar Bergman e a de August Strindberg; por fim, realiza-se uma análise do filme Depois do ensaio, com vista a identificar em que medida esse filme dialoga com a obra strindberguiana e de que maneira a teatralidade se apresenta. 


\section{Cinema e teatro: diálogos}

Contra aqueles que acusavam as adaptações de peças teatrais de "teatro filmado", André Bazin (2014) invocava uma nova relação entre teatro e cinema a partir de critérios formais. Filmes rodados nos anos 1940, como Henrique $V$ (1944), de Laurence Olivier, e $O$ pecado original (1948), de Jean Cocteau, a despeito de tomarem um texto dramático como base, distinguiam-se dos filmes derivados de peças teatrais que caracterizaram os chamados "filmes de arte". Considerado no início do século como uma forma de espetáculo vulgar ao gosto das classes mais populares, o cinema recorreu ao teatro e à literatura para dignificá-lo, ou seja, relegaram-se as formas anárquicas que versavam sobre fatos cotidianos, números de vaudeville, notícias, pornografia etc., e investiu-se na narrativização: essa foi a iniciativa de Paul Laffitte ao fundar, em 1908, junto aos membros da Comédie-Française, a companhia Film d'Art, que existiu até 1911, mas cujo legado perdurou por muitos anos. Devido aos esforços da Film d'Art, da Pathé e da Gaumont, o filme de arte difundiu-se rapidamente, adaptando temas mitológicos, eventos históricos e, sobretudo, obras de Shakespeare, Molière, Dickens, Balzac, entre outros.

Embora a intenção de elevar o cinema tenha sido válida, o principal problema dos filmes de arte era a precariedade da linguagem cinematográfica, pois, ainda que a nova arte tivesse sido fruto de avanços técnicos nunca antes vistos, a sua linguagem carecia de uma gramática própria, a qual só foi plenamente desenvolvida nos anos subsequentes, com o advento da montagem e do close-up, por exemplo. Devido ao fato de padecerem de excessiva frontalidade e do exagero nas atuações, bem como de se valerem de textos dramáticos e de atores já consagrados no teatro, os filmes de arte foram tachados pejorativamente de teatro filmado.

Em oposição ao teatro filmado, Bazin (2014) sugere o teatro cinematográfico. Para Bazin (2014, 163), "antigamente, a principal preocupação do cineasta parecia ser camuflar a origem teatral do modelo, adaptá-lo, dissolvê-lo no cinema. Agora, não somente ele parece desistir disso, como também salienta sistematicamente seu caráter teatral”. Isso se dá porque o cineasta moderno percebe a diferença entre o fato dramático e o fato teatral, sabendo que o primeiro está estritamente relacionado ao texto, e o segundo, ao espetáculo. Atendo-se apenas ao fato dramático, corre-se o risco de se recair no teatro filmado, como se o filme fosse apenas a fotografia da peça; em contrapartida, valorizando-se o fato teatral, tem-se o essencial do texto, o qual "determina modos e um estilo de representação" (Bazin 2014, 163). A visão de Bazin diferencia-se da de Barthes (1964, 41), para quem a teatralidade é "le théâtre moins le texte", visto que ele considera que mesmo o texto já traz marcas de teatralidade. É nesse sentido que o crítico reafirma a necessidade de, na adaptação para o cinema, ser o mais fiel possível ao texto original, em todas as suas 
potencialidades, afinal, "não é possível a um só tempo decidir ser fiel a ele [o texto] e afastá-lo da expressão para a qual tende" (Bazin 2014, 163).

Corolário disso é que as adaptações mais bem-sucedidas, em vez de se apropriarem apenas da fábula, buscam confirmar e enfatizar a convenção teatral do texto original. Comentando sobre Henrique V (1944), de Laurence Olivier, Bazin (2014, 166) afirma que "ao fazer cinema do teatro, ao denunciar de antemão pelo cinema a interpretação e as convenções teatrais, em vez de tentar camuflá-las, ele suprimiu os obstáculos do realismo que se opunha à ilusão teatral”. É que Olivier não apenas pretende que o público não esqueça da convenção teatral como também a frisa, o que se dá porque, em vez de apresentar a história diretamente diante das câmeras, ele encena a peça de Shakespeare, mostrando a coxia, o proscênio, os espectadores. Trata-se de um filme histórico sobre o teatro elisabetano cujo assunto é a representação de Henrique $V$.

Bazin (2014) assinala que outro filme que aposta na teatralidade é $O$ pecado original (1948), de Jean Cocteau, porquanto o diretor, em vez de usar o tradicional campo/contracampo, além de prescindir de uma análise psicológica conforme ponto de vista de uma personagem, opta quase totalmente por uma decupagem de acordo com o ponto de vista do espectador. Nas palavras de Bazin (2014, 171), "enquanto o cinema lhe permitia apreender o drama a partir dos pontos de vista múltiplos, ele adotava deliberadamente apenas o ponto de vista do espectador, único denominador comum do palco e da tela". Aqui, a relação entre espectador e tela é semelhante à do espectador no palco italiano (espectador de um lado e personagens de outro). Com isso, o espectador não mergulha na cena, é uma testemunha exterior à ação - uma posição diametralmente oposta à da câmera subjetiva, que criava a identificação do espectador com a personagem. Assim, não vemos o que a personagem vê, mas vemo-la olhar. Segundo Bazin (2014, 171), Cocteau utiliza "os recursos da câmera para acusar, salientar, confirmar as estruturas cênicas e seus corolários psicológicos”.

Interessantemente, Cocteau e Olivier, além de cineastas, são homens do teatro, assim como Orson Welles, Luchino Visconti, Ingmar Bergman e John Cassavetes, que se dividiam entre o teatro e o cinema. Talvez por isso souberam valorizar a teatralidade em suas adaptações ou aproximar-se das convenções teatrais mesmo em filmes com roteiros originais. $O$ fato é que esses cineastas vislumbraram, conforme salientava Bazin (2014, 190-191), que a solução "consistia em compreender que não se tratava de fazer passar para a tela o elemento dramático - intermutável de uma arte para outra - de uma obra teatral, e sim, ao contrário, a teatralidade do drama”. Desse modo, o teatro, em vez de perverter o cinema - tal como pensavam os críticos de vanguarda -, só tem a contribuir com ele e a enriquecê-lo. Contra os céticos, Bazin $(2014,191)$ postula 
que, a despeito de possuir suas leis e uma linguagem própria, o cinema muito tem a ganhar submetendo-se às outras artes: "e à medida que, rompendo com trapaças vãs e pueris, ele se propõe realmente a submeter-se e a servir". É esse espírito que leva Éric Rohmer $(1984,93)$ a dizer que "le cinéma moderne a plus à craindre de ses propres poncifs que d'une influence extérieure, comme celle du théâtre".

Antes de prosseguirmos, cabe aqui uma pergunta: que teatralidade é essa de que o cinema se serviria? Quando o cineasta Robert Bresson $(2005,55)$ diz que "nada se pode esperar de um CINEMA ancorado no teatro", sem dúvida, o teatro que ele tem em mente remete a "uma concepção de teatro imutável e imóvel, definido, antes de tudo, pela artificialidade" (Picon-Vallin 2008, 153). Essa teatralidade fundada na artificialidade baseia-se naquela que se impôs no teatro clássico, cujas características são a preponderância do texto, a rigidez e a afetação, o exagero na atuação, a frontalidade, as unidades de lugar e de tempo e artificialidade, ou seja, refere-se a

tudo aquilo de que os palcos tinham procurado se emancipar no curso da formidável aventura do teatro moderno - recorrendo à montagem, à dramaturgia do fragmento, à valorização do corpo em movimento, à reapropriação ativa e crítica de tradições distantes, à explosão do lugar cênico ou à busca do desenho impreciso das cenas etc. (Picon-Vallin 2008, 153).

De fato, aquela teatralidade como sinônimo de artificial e de afetação que Bresson (2005) e os vanguardistas rejeitavam deve ser deixada de lado, pois nada tem a oferecer de interessante ao cinema. Mas, se levarmos em consideração essa teatralidade moderna aventada por Picon-Vallin (2008), o próprio Bresson pode ser considerado um diretor que explora uma mise-en-scène teatral, na medida em que, por exemplo, propõe uma desautomatização do ator ou dissocia as suas ações de suas motivações, sendo que frequentemente essas são nulas. Em decorrência disso, cabe ao espectador preencher os sentidos e emoções sobre os quais os atores - ou modelos, como preferia Bresson - encontram-se em cada situação. Em todo caso, o que precisamos destacar é que a teatralidade não é estanque e fechada, mas é aberta e evolui constantemente, variando de época para época e até mesmo de dramaturgo para dramaturgo.

Picon-Vallin (2008, 158-159) aponta três modos pelos quais o cinema interage com o teatro: 1 . “fora de qualquer 'cineficação' artificial, não orgânica, não estruturante, a encenação de teatro é trabalhada pelo cinema"; 2. "presença obstinada, na produção cinematográfica, de filmes que partem de peças de teatro, que tomam o teatro por tema ou objeto"; 3. "filmes de Godard, Eisenstein, Bergman, Carné, Cassavetes, Fleischer, Fassbinder ou dos Irmãos Marx, são objeto de espetáculo na Europa ou nos EUA”. No tocante ao primeiro caso, trata-se tanto do registro de um espetáculo pelo cineasta como também da forma como o surgimento do cinema 
modificou a encenação teatral; quanto ao segundo, temos como exemplo filmes adaptados de uma peça - Macbeth (1948), de Orson Welles - ou que trazem o teatro como tema - Out 1, Noli me tangere (1971), de Jacques Rivette; por fim, temos filmes que são trazidos ao palco, como Persona (1966), de Ingmar Bergman, encenado pelo diretor português João Canijo em peça homônima. De acordo com Picon-Vallin (2008, 160), esse enriquecedor diálogo entre as duas artes deve-se ao "desejo de teatro pelo cinema, desejo de cinema pelo teatro, fascínio mútuo que se manifesta na criação dentro dos limites de cada uma das duas artes, na busca de uma parcela de eternidade, ou em um questionamento das formas".

A despeito de sua esclarecedora classificação de como se dá a interação entre essas duas mídias, Picon-Vallin (2008, 162) não a explora exaustivamente e, talvez por isso, limite-se a afirmar que "o filme de teatro é um filme, sem dúvida, mas dá testemunho - por intermédio dos atores - das duas artes: de seu encontro, não de sua fusão". Não obstante essa afirmação, cabe salientar que tem havido cada vez mais uma verdadeira fusão entre as duas mídias, muito além da adaptação ou da simples referência. Logo, deixando de lado o primeiro e terceiro modos de interação assinalados por Picon-Vallin (2008) e atendo-se apenas ao segundo, percebemos que os filmes que partem de peças ou tomam o teatro como tema podem ser divididos em três grupos de práticas intermidiáticas, a saber:

1. intermidialidade no sentido estrito de transposição midiática (Medienwechsel), denominada igualmente transformação midiática, a exemplo de adaptações fílmicas de textos literários, novelizações e assim por diante.

2. intermidialidade no sentido estrito de combinação de mídias (Medienkombination), que inclui fenômenos como ópera, filme, teatro, manuscritos iluminados/iluminuras, instalações computadorizadas ou Sound Art, história em quadrinhos ou, noutra terminologia, as chamadas formas multimídias, de mescla de mídias e intermidiáticas. [...]

3. intermidialidade no sentido de referências intermidiáticas (intermediale Bezüge), a exemplo das referências num texto literário a um certo filme, gênero fílmico ou cinema em geral (a escrita fílmica); idem as referências que um filme faz a uma pintura, ou que uma pintura faz a uma fotografia, dentre outras (Rajewsky 2012, 58).

Dentro dessa classificação, a primeira categoria visa a uma intermidialidade extracomposicional, enquanto a segunda e terceira categorias visam a uma intermidialidade intracomposicional, alterando não apenas o processo de formação, mas também a estrutura de uma entidade semiótica (Rajewsky 2012). Interessa-nos aqui, sobretudo, a segunda prática, porquanto é justamente a partir das combinações intermidiáticas que se desenvolvem novas formas, novos gêneros, os quais, por sua vez, combinar-se-ão produzindo outras mídias em seguida. Assim é que temos os chamados filmes de teatro 
(Picon-Vallin 2008) ou teatro cinematográfico (Bazin 2014). Contudo, é possível estabelecer as fronteiras entre uma mídia e outra?

Segundo Rajewsky (2012, 66), o que melhor determina as zonas fronteiriças são as convenções, ou seja, a relação entre midialidades "baseia-se na possibilidade de evocar, num receptor, aqueles modelos midiáticos específicos que lhe vem à mente”. Isso, porém, não diz tudo, pois, apesar de determinantes, as convenções (discursivas, sócio-históricas etc.) não são a única balizadora; de fato, "elas fundam-se adicionalmente em certas condições materiais e operativas, grande parte das quais estão sujeitas a mudanças históricas e geralmente tecnológicas, embora usufruam também de uma qualidade trans histórica" (Rajewsky 2012, 69). Podemos tomar como exemplo justamente as diferenças materiais e operativas entre cinema e teatro. Para Susan Sontag $(1987,107)$, a principal diferença entre essas duas mídias refere-se ao uso do espaço, quer dizer, "o teatro está confinado a um uso lógico ou contínuo do espaço. O cinema (por meio da montagem, isto é, através da mudança de plano - que é a unidade básica da construção fílmica) tem acesso a um uso alógico ou descontínuo do espaço”. Ismail Xavier $(2003,35)$ vai ao encontro do raciocínio de Sontag quando diz que, diferentemente do teatro, no cinema

A imagem que recebo compõe um mundo filtrado por um olhar exterior a mim, que me organiza uma aparência das coisas, estabelecendo uma ponte mas também se interpondo entre mim e o mundo. Trata-se de um olhar anterior ao meu, cuja circunstância não se confunde com a minha na sala de projeção. $\mathrm{O}$ encontro câmera/objeto (a produção do acontecimento que me é dado ver) e o encontro espectador/aparato de projeção constituem dois momentos distintos, separados por todo um processo. [...] Contemplo uma imagem sem ter participado de sua produção, sem escolher ângulo, distância, sem definir uma perspectiva própria para a observação.

O fato de o espaço no teatro ser contínuo e de o espetáculo ser imediato (isto é, sem mediação entre o olhar e a coisa olhada) favorece as condições materiais para a criação das convenções teatrais, ou melhor, cria a especificidade da mídia teatral: a teatralidade. Embora não exista uma essência absoluta a definir o que seja a teatralidade, podemos buscar alguns elementos que a constituem. No verbete "teatralidade" do Dicionário de Teatro, de Patrice Pavis (1999, 372), o seu significado aponta para "aquilo que, na representação ou no texto dramático, é especificamente teatral (ou cênico)", quer dizer, trata-se da "épaisseur de signes et de sensations qui s'édifie sur la scène à partir de l'argument écrit", conforme a definição de Barthes $(1964,41)$. É claro que isso não significa que um texto é mais teatral à medida que se presta facilmente à transposição cênica devido aos conflitos abertos e à troca rápida de diálogos (Pavis 1999), tampouco que o texto não comporte em si certa teatralidade - a despeito de o próprio Barthes excluir do texto a teatralidade. Com efeito, a teatrali- 
dade estaria naquele "texto que não pode se privar da representação e que, portanto, não contém indicações espaço-temporais ou lúdicas auto-suficientes" (Pavis 1999, 373). É de um paradoxo dessa natureza que advém a ambiguidade daquilo que vem a ser teatral: "ora significa que a ilusão é total; ora, ao contrário, que o jogo é demasiado artificial e lembra, sem trégua, que se está no teatro" (Pavis 1999, 373).

Acreditamos que a primeira caracterização seja muito mais afeita ao cinema, devido ao seu "realismo congênito" (Bazin 2012), do que propriamente à arte teatral, porquanto o teatro - consoante a sua etimologia ( $\theta \varepsilon \dot{\alpha} \alpha \tau \rho o v)$ : "o local de onde se vê" - implica a "constituição de um mundo 'real' no palco em oposição ao mundo 'real' da sala e, ao mesmo tempo, o estabelecimento de uma corrente de 'comunicação' entre o ator e o espectador” (Girault apud Pavis 1999, 373). Assim, o efeito de teatralidade é melhor obtido quando o teatro se apresenta como teatro, quando revela as regras que compõem o seu jogo. Em outras palavras, a teatralidade pura é que mostra a ruptura entre o "mundo real" e o "mundo encenado", entre a vida e a ficção. Sarrazac $(2013,57)$ diz:

Sou tentado a dizer que a ribalta e a cortina vermelha foram de fato abolidas a partir do momento em que o espectador foi convidado pelos atores ou qualquer outro condutor do jogo - diretor, encenador, autor, etc. - a não se interessar pelo evento do espetáculo, mas pelo advento, no centro da representação, do próprio teatro - daquilo que se chama teatralidade....

Quando Sarrazac comenta sobre esse convite feito ao espectador para participar do jogo teatral, a fim de romper com a ilusão dramática - tal como fizeram Pirandello e Brecht, por exemplo -, está se referindo obviamente às práticas metateatrais. E é justamente o metateatro que torna clara a própria natureza teatral, é o que revela o "vazio da representação". Em decorrência disso, continua Sarrazac (2013, 60), "o jogo estético desloca-se: não se trata mais de colocar em cena o real, mas de colocar em presença, confrontar os elementos autônomos - ou signos, ou hieróglifos - que constituem a realidade específica do teatro". Assim, em vez de apostar numa verossimilhança que visa mimetizar o real, tal como fazia o teatro naturalista, sem se dar conta de que, na verdade, o que se tinha era puramente uma cópia da realidade, o teatro moderno sabe não ser possível alcançar o real, por isso, aposta justamente em revelar o quanto possui de artificial. Com isso, em vez de submeter o teatro às aparências (cópias, no sentido platônico), opta pelo simulacro (cópias de segunda ordem), isto é, prefere demonstrar que a mimese é imperfeita e o real é inatingível, projetando o vazio das convenções para fora e revelando o jogo ao espectador, mostrando que é tudo mentira, é tudo teatro.

É a partir dessa ideia de simulacro que Michèle Garneau (2001, 30) percebe uma das formas de teatralidade no cinema mo- 
derno, isto é, como a irrupção da realidade na ficção: "au contact de la réalité, ou du document, ce que la fiction perd en vrai(semblable), elle le gagne en faux-semblant. La fiction, s'exposant comme quelque chose d'extérieur à la réalité, se fait théâtre de la fiction, se théâtralise". É que, diante do contato com o mundo "real" do espectador, a descrença deixa seu estado de suspensão, sendo que aquilo que seria tido como verossímil, devido à imersão naquele mundo fechado, sofre uma ruptura.

A segunda forma pela qual o cinema moderno sente os efeitos de teatralidade se dá pela irrupção do olhar na representação, ou seja, quando a personagem observa em vez de agir, e nós olhamos o seu olhar. Mais do que isso: o olhar teatral define-se por certa frontalidade, pela distância entre ator e plateia e, sobretudo, pela possibilidade de escolher o ponto de vista: "en effet, l'oeil du spectateur de théâtre peut à tout moment s'affranchir des suggestions de la mise en scène, déchiffrer l'espace à son gré, choisir une focalisation et poursuivre la lecture du spectacle à partir de ce point de vue" (Garneau 2001, 34). É precisamente esse regime de olhar que caracteriza boa parte do cinema do pós-guerra, tanto a escola neorrealista quanto os filmes de Orson Welles que fazem uso da fotografia em profundidade de campo. Por fim, há também a irrupção do corpo do ator na representação, que nada mais é do que "l'artifice du corps", "l'emprunt des gestes et des intonations, en invoquant le gestus, qui est aussi bien gestuel que vocal" (Garneau 2001, 35).

Em maior ou menor medida, esses efeitos de teatralidade estão presentes nas obras de cineastas como Laurence Olivier, Orson Welles, Luchino Visconti, John Cassavetes, Jacques Rivette, Chantal Akerman, Theo Angelopoulos, Rainer Werner Fassbinder, Alain Resnais, Ingmar Bergman, Manoel de Oliveira, Peter Greenaway, Alejandro Jodorowsky, entre outros. A diversidade de cineastas que tiram proveito da mídia teatral para a configuração de uma mise-enscène que renova a linguagem cinematográfica diz respeito também à diversidade de níveis de teatralidade no cinema, que podem se referir ao enquadramento, à cenografia, à iluminação, à voz do ator, bem como ao seu deslocamento no quadro. Para Gurgel (2011, 147), "a teatralidade pode afetar, ainda, as estruturas narrativas e as formas dramatúrgicas, através da divisão em atos, do repertório escolhido, das funções do diálogo e da decupagem das cenas".

Assim, com base no que foi exposto a partir de Bazin, PiconVallin, Garneau e Gurgel, é possível observar de que modo a teatralidade se anuncia no filme Depois do ensaio (1984), dirigido por Ingmar Bergman.

\section{Bergman encena Strindberg}

Apesar de mais conhecido por sua carreira como cineasta, Ingmar Bergman manteve uma prolífica produção teatral, tanto como drama- 
turgo quanto como diretor, tendo realizado cerca de 170 montagens. Henrik Ibsen, Molière, William Shakespeare e August Strindberg foram os dramaturgos a que Bergman mais recorreu, sendo que, entre 1940 e 2003, levou a obra de Strindberg aos palcos por vinte vezes: somente a peça $O$ sonho foi encenada em 1970, 1977 e 1986 - fora a versão televisiva de 1963.

A sua relação com Strindberg data de sua adolescência, quando, aos doze anos, leu a primeira obra do dramaturgo e, aos treze, adquiriu a Obra Completa em 55 volumes, da edição anotada de John Landquist. Já como estudante de literatura na Universidade de Estocolmo, "he wrote a paper comparing Strindberg's pilgrimage play The Keys of Heaven with his Dream Play" (Törnkvist 2013, s.p.).

$\mathrm{O}$ espectro strindberguiano invade também a obra cinematográfica de Bergman, tanto que, na cena final de Fanny $e$ Alexander (1982), a personagem Helena Ekdahl, convidada por sua nora a fazer parte de uma montagem de Strindberg, lê um trecho do célebre Prefácio de $O$ sonho: "Tudo pode acontecer, tudo é possível e verosímil. Deixam de existir tempo e espaço. A partir de uma insignificante base real, o autor dá livre curso à imaginação, que multiplica os locais e as ações" (Strindberg 1978, 19) ${ }^{1}$. Segundo Törnkvist (2013, s.p.), "this passage is not only a key to Bergman's last feature film. It is a key also to other works by him, on stage and screen. The interweaving of reality and fantasy, objectivity and subjectivity, runs through his entire work". Ora, para atestarmos essa afirmação a partir dos exemplos mais óbvios, basta pensarmos em Morangos silvestres (1957), em O silêncio (1963) ou em Persona (1966), filmes em que o entrelaçamento entre realidade e fantasia, entre a vida interior e o mundo exterior, se dá de tal modo que essas duas instâncias se confundem. Para Törnkvist (1995, 211), "the border between objective and subjective reality is blotted out. In all these cases, Bergman subtly applies the Strindbergian principle of half-reality". Esse princípio consiste em ver a realidade do ponto de vista dos sonhos, a fim de criar a impressão de que essas duas ordens não são tão discerníveis. Em seu ensaio sobre Persona, Sontag (1987, 126) afirma que "a dificuldade de Persona deriva do fato de que Bergman recusa o tipo oferecido de sinalização nítida para separar as fantasias da realidade". Tal esfacelamento da realidade pela inserção do sonho é apenas uma das aproximações entre Bergman e Strindberg. O fato é que o cineasta traduz para a linguagem cinematográfica elementos constantes da obra do dramaturgo sueco.

Não é de espantar que o próprio Bergman tenha chegado a declarar: "my films are only a distillation of what I do in the theater" (Bergman apud Törnkvist 1995, 12). A mise-en-scène de seus filmes persegue constantemente um efeito de teatralidade, quer seja pelo uso da fotografia em profundidade de campo, que obriga o especta-

\footnotetext{
${ }^{1}$ Nessa passagem, valemo-nos na tradução portuguesa de 1978.
} 
dor a escolher o que quer ver no quadro (tal como se dá com o público no teatro), quer seja pela preferência aos movimentos de câmera em detrimento dos cortes, ou ainda pela eliminação de enquadramentos e ângulos tipicamente cinematográficos, dando preferência à frontalidade e ao deslocamento lateral dos atores. É claro que nem sempre há em todos os filmes o mesmo tipo de expediente, até porque, muitas vezes, a teatralidade é assimilada à própria estrutura de seus filmes.

Se lançarmos os olhos sobre os filmes do início de sua carreira, veremos que nada mais são do que peças disfarçadas, pois se estruturam em cenas e atos, como as comédias Uma lição de amor (1954) ou Sorrisos de uma noite de amor (1955). Mas Bergman aproxima-se do teatro, sobretudo, ao inserir uma peça dentro do filme ou trazendo elementos teatrais para o cotidiano das personagens: em Noites de Circo (1953), o circo itinerante aparece como antípoda do teatro; em Sorrisos de uma noite de amor, a protagonista é uma atriz teatral, e seu coquetismo penetra a vida "real"; em O sétimo selo (1956), a companhia itinerante encena um espetáculo cômico para um público castigado pela peste negra; em $O$ rosto (1958), o farsante realiza num palco sessões de hipnose a uma plateia burguesa; em $O$ olho do diabo (1960), inspirado em Don Juan, de Molière, a trama apresenta-se como uma farsa, além de haver um prólogo e um epílogo que denotam que o filme é apenas ficção; em Através de um espelho (1961), os dois irmãos, Minus e Karin, encenam uma peça tchekhoviana para o pai; em Persona (1966), a protagonista é uma atriz que se recusa a agir e a falar; em $O$ rito (1969), três atores são interrogados por um juiz devido à acusação de encenarem uma peça obscena; em Fanny e Alexander (1982), as personagens habitam o mundo do teatro; por fim, em Depois do ensaio (1984), a ação se desenrola num palco após o ensaio da peça $O$ sonho, de Strindberg. Ora, o fato de o teatro estar presente em cada um desses filmes serve para assinalar os temas centrais da obra bergmaniana, a saber: máscara e rosto, fingimento e autenticidade, sonho e realidade, enfim, teatro e vida.

Törnkvist (1995) aponta que Bergman e Strindberg trazem em comum em suas obras: o rompimento da linha entre subjetividade e objetividade; o tema do desmascaramento; a incomunicabilidade; a estrutura em jornada/estações; e a relação com formas musicais (música de câmara, oratório etc.). Com efeito, como já foi mencionado, o rompimento entre realidade e fantasia atravessa toda a sua obra; quanto ao desmascaramento, verificamo-lo em $O$ rosto - a humilhação do hipnotizador - e Gritos e sussurros - a interação forçada entre as irmãs revela o ressentimento recalcado; a incomunicabilidade está tanto nos filmes da Trilogia do Silêncio (Através de um espelho, Luz de inverno e $O$ silêncio), como também no silêncio da atriz em Persona e nos segredos de Egerman em Da vida das marionetes; a estrutura em estações aparece mormente em Morangos silvestres; já a relação com 
música está tanto na forma-sonata de Sonata de outono quanto em $O$ sétimo selo, que foi denominado por Bergman como um oratório.

O parentesco de Bergman com Strindberg acentua-se na exploração daquilo que o dramaturgo, na última fase de sua carreira, denominou "peça de câmara", isto é, uma forma emprestada da música que, no drama, se prestaria a investigar a intimidade, as paixões secretas e as motivações psicológicas das personagens. Segundo Törnkvist $(1995,16)$, "with his chambers plays, Strindberg has renewed drama. By applying Strindberg's idea to film, Bergman has renewed film art”. O próprio Bergman designa os filmes Através de um espelho, Luz de inverno, O silêncio e Persona como peças de câmara. Em suas palavras: "they are chamber music - music in which, with an extremely limited number of voices and figures, one explores the essence of a number of motifs" (Bergman apud Törnkvist 1995, 16). Na análise que faz de Depois do ensaio, Anna Sveinbjorsson $(1994,30)$ diz que este filme também assume a forma de uma peça de câmara: "a single set, one act and three characters. Sven Nykvist, the cinematographer had limited possibilities regarding the inventive camera angles". Na verdade, o filme oscila entre os close-ups cinematográficos - que desnudam os rostos vulneráveis, perscrutando as verdades ocultas - e as longas tomadas, algo teatrais - em que as personagens dissimulam e pregam peças umas nas outras (Törnkvist 1995). Enfim, temos também, no plano formal, o motivo da máscara versus rosto, da subjetividade versus objetividade, do sonho versus realidade.

\section{Depois do ensaio d'O sonho}

Depois do ensaio foi produzido originalmente para a televisão sueca, em 1984, e lançado nos cinemas mundo afora no mesmo ano. Tratase, segundo Bergman (1996, 220), de "uma obra de televisão cinematográfica que fala de teatro". O filme gravita em torno de um diretor de teatro - Henrik Vogler (Erland Josephsson), alter ego de Bergman - que está trabalhando na sua quinta montagem de $O$ sonho, de Strindberg, e que, depois de um ensaio, conversa com Anna Egerman (Lena Olin), a atriz que interpretará na peça Agnes, a filha de Indra. A conversa traz à tona a importância do teatro em suas vidas, bem como os ressentimentos em relação a Rakel Egerman (Ingrid Thulin), ex-amante de Vogler e mãe de Anna. A partir dessas três personagens, Bergman revisita Strindberg e o tema do teatro como metáfora das ilusões deste mundo, e faz um balanço de sua carreira.

Como o próprio título indica, Depois do ensaio aponta para a fórmula shakespeariana de que o mundo é um palco (All the world's a stage), pois o filme, de fato, inicia-se depois do ensaio da peça, logo, seria o momento no qual as personagens estariam vivendo a "vida real" - em oposição ao mundo do teatro - no entanto, podemos considerar que, se a ação começa depois do ensaio, o que se 
desenrola diante dos nossos olhos é a própria encenação da peça não de Strindberg, mas sobre ele, ou melhor, a partir de sua obra. Comentando o início de Depois do ensaio, Törnkvist (2013, s.p.) afirma que "the initial shot imitates the Prologue of the play that is on Vogler's mind: Indra's Daughter's descendence to Earth. Likewise, his turning the light of the lamp next to him on and off reveals that the following passage of the play he is rehearsing is on his mind". Ou seja, enquanto na peça o apagar das luzes é a passagem do prólogo no céu para a descida na terra; no filme, o despertar de Vogler é a passagem do sono à vigília, do sonho à realidade - ainda que seja a realidade do palco. Assim como Agnes vê com estranheza o mundo dos homens, Vogler diz não reconhecer o lugar no qual se encontra, tanto que diz: "Alguma coisa mudou... misteriosa e elusivamente" (Depois do ensaio, 1984). Mas, mal tendo tempo de se habituar, Anna surge em cena, e os dois passam a dialogar - algo semelhante acontece em $O$ sonho, pois Agnes repentinamente trava relações com o Vidraceiro, com o Oficial, entre outros.

Para além dos paralelos estruturais entre o filme e a peça, há uma cena em Depois do ensaio em que a teatralidade evidencia-se por algo que Bergman (1988, 37), comentando sobre o fascínio que a peça de Strindberg exerceu sobre ele, em Lanterna Mágica, chamou de "magia da arte de representar": é o momento em que Vogler conta a Anna como se sentiu afetado pela Cena $\mathrm{VIII}^{2}$ de $O$ sonho:

Quando tinha 12 anos, vim aqui com um músico que tocava o órgão. Noite após noite, eu ficava sentado lá na torre de luz assistindo às cenas do casamento do advogado com a filha de Indra. Foi a primeira vez que senti a magia da interpretação. O Advogado segurava um grampo de cabelo entre os dedos. "Olhe isso aqui, tem dois dentes, mas um alfinete. São dois, mas é um. Se eu o endireitar, ele se torna uma entidade única. Se eu entortá-lo, ele se torna dois, sem deixar de ser um. Isso significa que esses dois são um. Mas se eu quebrá-lo, agora, eles são dois, dois!” Não havia prendedor, mas eu o vi. Foi assim que tudo começou (Depois do ensaio, 1984).

\footnotetext{
2 "Repara neste aqui! ... Duas hastes... mas um único gancho! Dois, e que não fazem mais do que um! Se o endireitar, fica só uma haste. Se o dobrar, há duas, mas sem deixarem, por isso, de ser uma só! Repara: dois fazem um! (Parte o gancho e deita fora os pedaços) (Strindberg 1978, 104-105).
} 


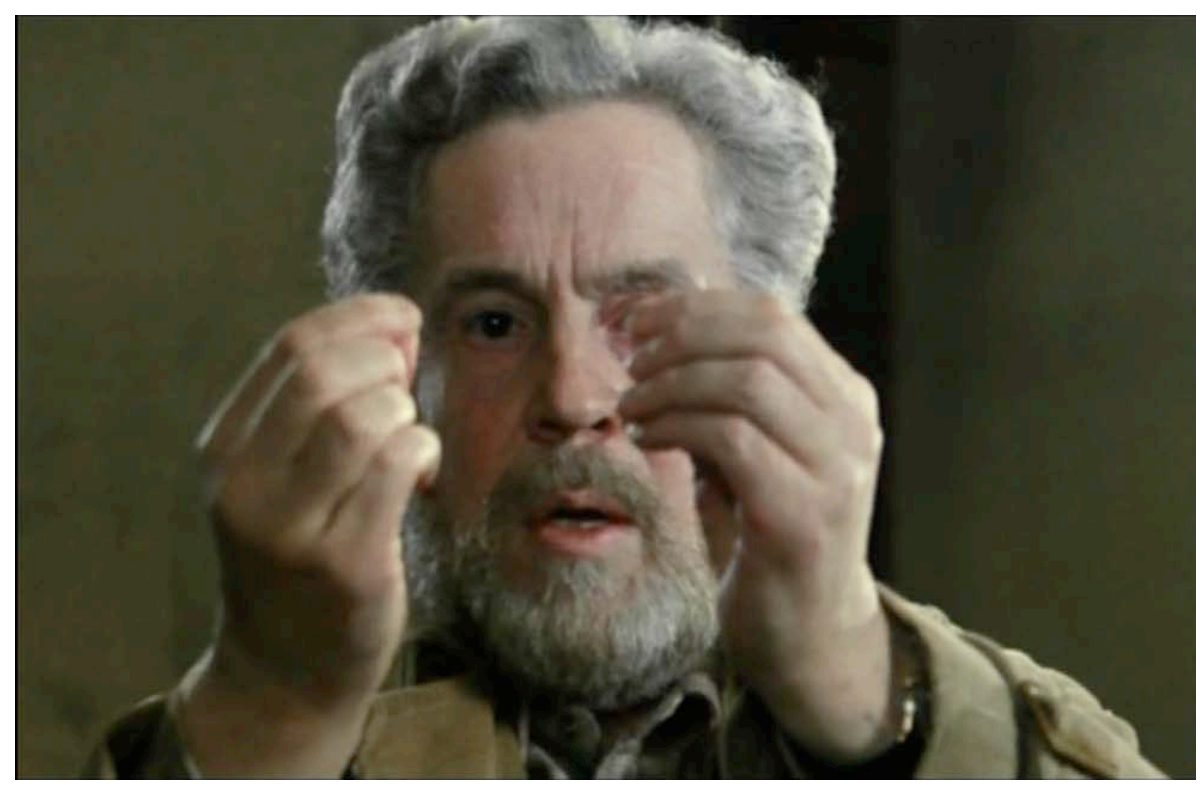

Imagem 1: "Não havia prendedor, mas eu o vi. Foi assim que tudo começou" Depois do ensaio (I. Bergman, 1984) (c) AB Svensk Filmindustri

Assim que termina sua narração, temos o único flashback de todo o filme, em que aparece Vogler, com a idade de 12 anos, exatamente sob a torre do proscênio. Embora à primeira vista a imagem seja redundante ao relato narrado, interessantemente, o ator que faz o jovem Vogler é Bertil Guve, que interpreta Alexander, o alter ego de Bergman em Fanny e Alexander. Comentando sobre a sequência do grampo de cabelo, Törnkvist $(2003,125)$ diz:

When Vogler relates to Anna how he, at the age of twelve, witnessed the hairpin sequence in A Dream Play from the wings of the theater, he actually replays the sequence, turning himself into the Lawyer who first describes, then breaks the hairpin, the symbolic portrayal of the man-woman relation. Bergman includes this intertextual element because its metaphorical presentation of the relationship between the Daughter and the Lawyer in Strindberg's play prefigures the imagined relationship between Anna and Vogler in After the rehearsal. Walking around the stage - a movement indicating the passage of time - Vogler and Anna indulge in fantasies about how their relationship might develop. Like the marriage scene in $A$ Dream Play, the sequence shows in telegraphic style the development from early infatuation and harmony to disagreement and divorce.

Ao representar a cena do Advogado diante de Anna, Vogler sai da posição de diretor e assume a de ator; além disso, conforme o enunciado por Törnkvist, ele encarna o Advogado, e Anna, a Filha de Indra, quando, no final do filme, os dois tecem fantasias sobre o início e o fim de sua relação - embora ele diga a ela: "Eu me recuso a fazer parte do seu drama" (Depois do ensaio, 1984). De fato, Vogler tem plena consciência de seu papel e sabe dos excessos teatrais que comete, como, por exemplo, quando explica a Anna a sua visão sobre 
a profissão. A sua voz em off interpõe-se à cena: "Por que entro nessa teatralidade ridícula, essa paródia de convicção que se tornou amarga e decadente?" (Depois do ensaio, 1984). Ao lado do flashback supracitado, o expediente da voz em off é um dos raros momentos em que a linguagem cinematográfica se sobressai durante o filme, pois a teatralidade é preponderante - o que pode ser percebido quando Vogler diz a Anna que os objetos que estão no palco não possuem autenticidade, não fazem parte do "mundo real", mas do próprio universo teatral: a poltrona foi usada numa montagem de $O$ pai, de Strindberg; o sofá, em Hedda Gabler, de Ibsen; a mesa, em Tartufo, de Molière; as cadeiras, em $O$ sonho.

Esse empréstimo que a vida faz do teatro está contido também no relato que Anna faz sobre as brigas da mãe com o pai:

Via mamãe brigar com o papai. Eu usava as suas vozes, seus gestos e entonação. Às vezes, um diálogo de uma peça era usado, adaptado para a ocasião. [...] Será que papai não percebia o quão teatral ela era? Como ela chorava com um olho e com o outro observava a reação dele? Como ela dirigia uma peça, impondo os diálogos mais estranhos? (Depois do ensaio, 1984).

Ressalta-se, da passagem acima, a maneira como a mãe (Rakel) dissimulava, fingia os sentimentos, agia na vida como se estivesse no palco. De fato, embora recrimine a mãe, Anna também é censurada por Vogler devido à artificialidade que demonstra ao interagir com ele:

VOGLER: Você é pior atriz quando conversamos privadamente do que no trabalho. Abandone a atriz privada! Ela rouba a energia da atriz de verdade, frustrando impulsos que você poderia usar no palco.

ANNA: Agradamos as pessoas quando mostramos o rosto que esperam. Alguém espera que fiquemos felizes com um presente, então ficamos. Alguém quer que demonstremos amor e recebemos amor em troca. [...] Como posso me proteger do mundo sem atuar? (Depois do ensaio, 1984).

Esse diálogo guarda parentesco com outro filme de Bergman, Persona. Nesse filme, a atriz (Elizabeth Vogler) mantém-se em mutismo e recusa-se a agir, pois não quer mentir, não quer ser inautêntica nas relações interpessoais, mas também necessita se proteger do mundo, que exige dela sorrisos, caretas, afabilidade. Tem-se a dicotomia atriz privada versus atriz no palco, pois, se estamos no theatrum mundi, mesmo na "vida real" temos de atuar, performatizar. Daí a frase que Vogler diz a certa altura: "Tudo é representação; nada é" (Depois do ensaio, 1984); ou seja, não existe autenticidade, o mundo é um palco sobre o qual encenamos desde que nascemos. A propósito da frase dita por Vogler, ela está presente em A sonata dos espectros, de Strindberg, e traz em seu bojo o tema principal de $O$ sonho: nada é o que parece, pois o véu de Maia oculta a 
unidade do mundo, fazendo-nos vê-lo como cindido, repleto de contradições ${ }^{3}$. Segundo Törnkvist $(2003,124)$,

Bergman sets his entire teleplay in a theather but selects another area particularly prone to representing illusion: the stage. [...] Just as the signifier - the stage - represents this world and in this sense is unreal, so the signified - this world - in turn merely represents or mirrors the true reality. To experience life as unreal, half-real or dreamlike is therefore both natural and truthful.

Assim, considerando que situar um filme no espaço do teatro salienta o rompimento das barreiras entre realidade e ficção, não é de estranhar a repentina aparição de Rakel, apesar de já ter morrido há muito tempo. Afinal, sonho e vigília correspondem-se mutuamente. Para Bergman (1996, 220), "na obscuridade de um palco vazio, durante a hora mais silenciosa de um teatro, entre quatro e cinco da tarde, não são poucas as recordações que voltam a nós”. A sequência em que Rakel aparece em cena é uma das mais interessantes para se pensar a teatralidade em Depois do ensaio, porquanto promove uma duplicação especular do tempo - tal como Strindberg postulava no Prefácio de $O$ sonho -, fazendo com que passado e presente coexistam ao mesmo tempo e as personagens desdobrem-se.

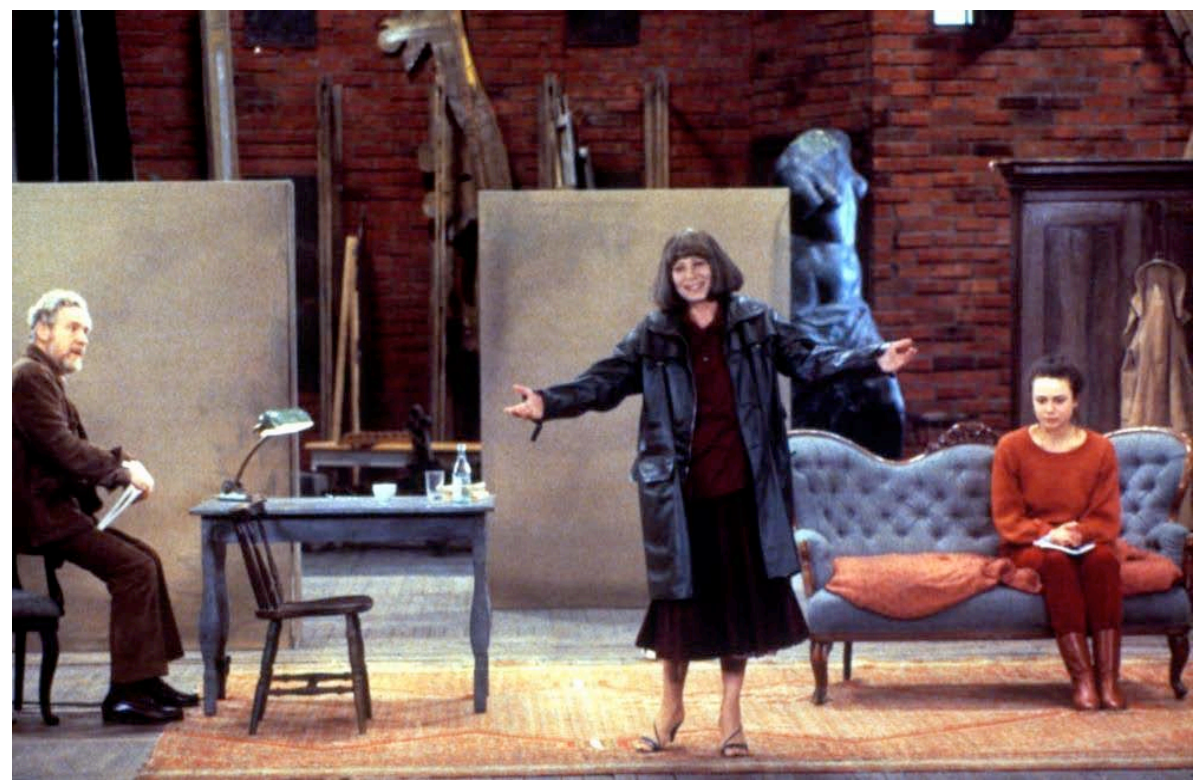

Imagem 2: O fantasma de Rakel em cena | Depois do ensaio (I. Bergman, 1984) (c) AB Svensk Filmindustri

\footnotetext{
3 "No alvorecer dos tempos, antes de o Sol ter começado a brilhar sobre todas as coisas, Brahma, a força divina original, deixou-se seduzir por Maya, a mãe do mundo. Esta união entre a divina matéria original e a matéria terrestre provocou a queda do céu. Daí que o mundo, a vida e os homens mais não sejam do que um fantasma, uma aparência um sonho" (Strindberg 1978, 204).
} 


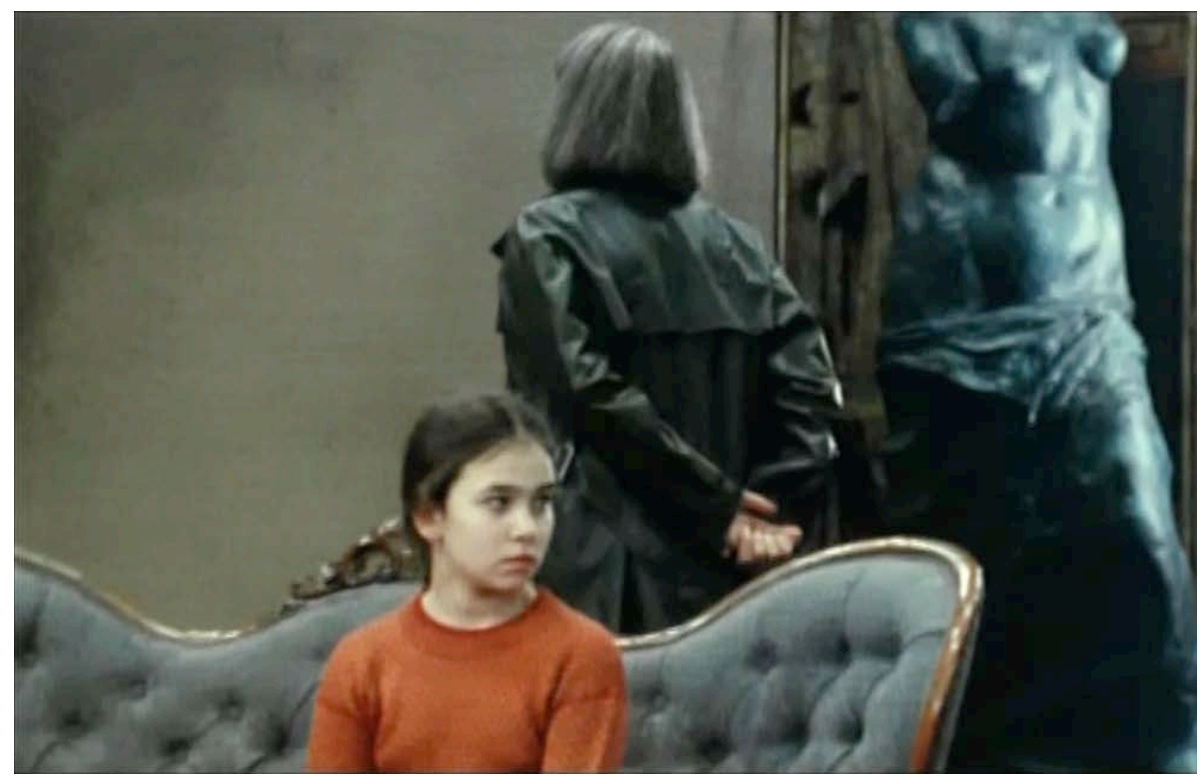

Imagem 3: Anna Egerman quando criança | Depois do ensaio (I. Bergman, 1984) (C) AB Svensk Filmindustri

A duplicação se dá porque, tão logo Anna rememora lembranças da mãe em seu relato, Rakel surge no palco, sendo que Anna mantém-se passiva e distante, como espectadora das próprias memórias, enquanto Vogler interage com a amante falecida. Bergman, em vez de recorrer à facilidade do flashback, opta por meio da decupagem da cena, sobretudo pelo uso do campo/contracampo, em enquadrar apenas Vogler e Rakel, criando a impressão de que Anna não está mais presente. Com efeito, quando aparece, Anna permanece imóvel, mas com a idade de 12 anos - a atriz Nadja PalmstjernaWeiss toma o lugar de Lena Olin em boa parte da cena -, ainda que vestindo as mesmas roupas vermelhas. Enquanto isso, Vogler é o mesmo: veste as mesmas roupas e interage com Rakel tal como interagia com Anna; o seu passado e o seu presente são um só. A fronteira temporal é, portanto, totalmente esfacelada - semelhantemente ao que Bergman fizera em Morangos silvestres, quando o velho professor Isak Borg comunicava-se com o seu passado com naturalidade, a despeito de ele já estar idoso e os demais estarem jovens. Em Depois de ensaio, apesar de se valer de um expediente mais simples pela mera irrupção em cena de uma personagem já morta, de um passado distante -, o efeito é mais radical, pois o espectador não consegue mais distinguir o presente do passado, o sonho da realidade. É que o artifício de que se vale Bergman não é cinematográfico, mas sim teatral, se considerarmos que o teatro costuma exigir do espectador uma suspensão total da descrença, tendo ele mesmo que ajudar a criar a fantasia indo além do que está posto em cena, ao passo que o cinema, conforme preconiza Bazin (2014), apresenta as imagens ao espectador como se fossem reais. A teatralidade do filme reside, nesse caso, em exigir do espectador do filme que ele aja ativamente, tal como se fosse um espectador de uma peça. 
Segundo Törnkvist (2003), muitas das situações apresentadas no filme retomam motivos e situações das peças de Strindberg que Bergman encenou ao longo da vida. Quando Vogler diz a Anna que perdeu um dente antes do ensaio e que temia ficar ridículo diante dela, Bergman está se apropriando de uma cena da comédia em um ato chamada Första Varningen, de 1893, na qual o marido perde um dente. A aparição de Rakel ressoa a aparição do fantasma da Leiteira em A sonata dos espectros; o pretexto de Anna para voltar ao teatro e conversar com Vogler, dizendo que perdera um bracelete, é semelhante ao truque da Jovem para atrair a atenção do Estudante nessa mesma peça. Por fim, o último diálogo do filme também retoma $A$ sonata dos espectros, visto que, pouco antes de sair, Anna hesita, volta-se para Vogler e lhe pergunta: "Está ouvindo os sinos da igreja?" (Depois do ensaio, 1984). Ele responde que não, pois está com a audição ruim. Assim que ela se vai, a sua voz em off diz: "O que me preocupava mais nesse momento era provavelmente o fato de não escutar os sinos da igreja" (Depois do ensaio, 1984). Um barulho de porta se fechando, e o filme termina. Para Törnkvist $(2003,123)$,

The cryptic ending of After the rehearsal may also be understood as an echo of the close of The Ghost Sonata, at least for the reader. Whereas the reader here learns that "far away, as from another world, the tolling of bells and the sirens of ambulances are heard" - a discordant analogue to the music heard from the Isle of the Dead at the end of The Ghost Sonata. [...] the viewer is more inclined to see it as a warning of approaching deafness - fatal to a director - as well as of approaching death.

A possível surdez de Vogler pode significar a morte que se aproxima, como na peça supracitada, mas também que ele não é mais capaz de escutar Strindberg, de senti-lo, logo, incapaz de realizar outra montagem de $O$ sonho.

Enfim, observamos, em Depois do ensaio, que Bergman vale-se de uma mise-en-scène tipicamente teatral, além de trazer o teatro como assunto, fazendo com que a ação se desenrole num palco. Além disso, devido ao fato de o filme ter como premissa uma montagem da peça $O$ sonho, o cineasta realiza um profícuo diálogo com a obra de August Strinderg tanto no conteúdo quanto na forma. Ainda que não seja a sua obra-prima, o filme é o coroamento de toda a sua carreira, quer seja no teatro, quer seja no cinema. Mais do que a fórmula "Bergman fez mais um filme de Bergman", o apropriado aqui seria: Bergman resumiu a obra de Bergman, reinventando-a. É justamente disso que trata Depois do ensaio: um balanço inventivo da própria obra.

\section{Considerações finais}

Partindo das reflexões de Bazin (2004) acerca do que ele denomina "teatro cinematográfico", bem como das definições de Picon-Vallin 
(2008) sobre os chamados "filmes de teatro", buscamos refletir sobre as práticas intermidiáticas que envolvem as duas mídias e pensar de que maneira o cinema moderno esquiva-se da teatralidade baseada na artificialidade, na preponderância do texto, na afetação e na frontalidade, e alcança uma teatralidade aberta, em devir, que altera as convenções cinematográficas no tocante à montagem, aos enquadramentos, à mise-en-scène, à decupagem das cenas e à própria estrutura narrativa.

Depois, com base nos estudos de Egil Törnkvist (1995, 2003, 2013), buscamos aproximações entre as obras de Ingmar Bergman e de August Strindberg, verificando que, na obra de ambos, acontece um esfacelamento da realidade pela inserção dos sonhos, rompendo, assim, a linha entre subjetividade e objetividade. Além disso, Bergman apropria-se de temas frequentes na obra de Strindberg, como o desmascaramento, a incomunicabilidade, o inferno conjugal, além, de recorrer, às vezes, à estrutura em jornada/estações ou a formas musicais - como se dá com as chamadas "peças de câmara".

Por fim, na análise do filme Depois do ensaio, vimos como se dá o diálogo de Bergman com a obra strindberguiana, tanto no plano formal quanto na exploração temática e nas referências intertextuais. A teatralidade na obra de Bergman ultrapassa a renovação da linguagem cinematográfica pela adição de recursos oriundos do teatro; com efeito, a teatralidade transparece como elemento central dos seus filmes - em especial, em Depois do ensaio - na medida em que exploram as dicotomias máscara/rosto e sonho/realidade, e as personagens debatem-se em meio a essas contradições.

Segundo o site Ingmar Bergman Foundation ${ }^{4}$, entre 1996 e 2011, o argumento de Depois do ensaio foi levado aos palcos por 25 vezes, tendo percorrido diversos lugares da Europa, como Moscou, Gênova, Varsóvia, Atenas, Belgrado, Bruxelas, Barcelona e Praga. Assim, se, por um lado, como se demonstrou neste artigo, a obra cinematográfica de Bergman mantém uma rica interação com o teatro e, sobretudo, com a obra de Strindberg; por outro, para além do caráter provisório a que muitos roteiros se prestam, o texto bergmaniano atesta a sua perenidade ao tornar-se uma adaptação teatral - realizando, portanto, um caminho inverso do que sói acontecer. Isso significa que, a despeito do gracejo de Bergman sobre o cinema ser sua amante enquanto o teatro era sua mulher, esses papéis são permutáveis dentro da sua obra: ut cinema theatrum...

\footnotetext{
${ }^{4}$ Disponível em: http://ingmarbergman.se/en/production/after-rehearsal-0.
} 


\section{BIBLIOGRAFIA}

Barthes, Roland. 1964. Le théâtre de Baudelaire. In Essais critiques, 41-47. Paris: Éditions du Seuil.

Bazin, André. 2014. "Teatro e cinema”. In O que é o cinema?, 155198. Trad. de Eloisa Araújo Ribeiro. São Paulo: Cosac Naify.

Bergman, Ingmar. 1996. “Depois do ensaio”. In Imagens, 220-226. Trad. de Alexandre Pastor. São Paulo: Martins Fontes.

-_- 1988. Lanterna Mágica. Trad. de Alexandre Pastor. Rio de Janeiro: Guanabara.

Bresson, Robert. 2005. Notas sobre o cinematógrafo. Trad. de Evaldo Mocarzel. São Paulo: Iluminuras.

Garneau, Michèle. 2001. "Effets de théâtralité dans la moderne cinématographique”. L'Annuaire théâtral, 30 (Automne): 2440 .

Gurgel, Gabriela Lírio. 2011. "Cinema e teatro: interfaces”. Concinnitas, 19 (2): 146-154.

Pavis, Patrice. 1999. “Teatralidade”. In Dicionário de Teatro, 371-374. São Paulo: Perspectiva.

Picon-Vallin, Béatrice. 2008. "O filme de teatro". In A cena em ensaios, 151-163. Trad. de Fátima Saadi, Cláudia Fares e Eloisa Araújo Ribeiro. São Paulo: Perspectiva.

Rajewsky, Irina. 2012. “A fronteira em discussão: o status problemático das fronteiras midiáticas no debate contemporâneo sobre intermidialidade". In Intermidialidade e estudos interartes: desafios da arte contemporânea, org. Thaïs Flores Nogueira Diniz e André Soares Vieira, 51-73. Belo Horizonte: Rona Editora; FALE/UFMG.

Rohmer, Éric. 1984. "Le film et les trois plans du discours: indirect/direct/hyperdirect”. In Le gôut de la beauté, 93-99. Paris: Éditions de l'Étoile.

Sarrazac, Jean-Pierre. 2013. "A invenção da teatralidade”. Trad. de Sílvia Fernandes. Sala Preta, 13 (1) (jun.): 56-70.

Sontag, Susan. 1987. "Persona, de Bergman". In A vontade radical: estilos, 121-141. Trad. de João Roberto Martins Filho. São Paulo: Companhia das Letras.

—_—. "Teatro e filme". 1987. In A vontade radical: estilos, 99-120. Trad. de João Roberto Martins Filho. São Paulo: Companhia das Letras.

Strindberg, August. 1978. O sonho. Trad. de João da Fonseca Amaral. Lisboa: Editorial Estampa. 
Sveinbjornsson, Anna. 1994. "Theatrical images in Bergman's films." MA Thesis (Department of Theatre, Film and Creative Writing), University of Stockholm.

Törnqvist, Egil. 2003. "Bergman's After the rehearsal on television”. In Bergman's muses: Aesthetic versatility in film, theatre, television, and radio, 117-128. Jefferson (USA): McFarland \& Company.

_-_. 2013. "Strindberg in Bergman". Ingmar Bergman, http://ingmarbergman.se/en/universe/strindberg-bergman.

-_- 1995. Between stage and screen: Ingmar Bergman directs. Amsterdam: Amsterdam University Press.

Xavier, Ismail. 2003. O Olhar e a Cena: Melodrama, Hollywood, Cinema Novo, Nelson Rodrigues. São Paulo: Cosac Naify.

\section{FILMOGRAFIA}

Noites de Circo [longa-metragem]. Dir. Ingmar Bergman. SandrewProduktion, Suécia, 1953. 92 mins.

Uma lição de amor [longa-metragem]. Dir. Ingmar Bergman. Svensk Filmindustri, Suécia, 1954. 96 mins.

Sorrisos de uma noite de amor [longa-metragem]. Dir. Ingmar Bergman. Svensk Filmindustri, Suécia, 1955. 108 mins.

O sétimo selo [longa-metragem]. Dir. Ingmar Bergman. Svensk

Filmindustri, Suécia, 1956. 96 mins.

Morangos silvestres [longa-metragem]. Dir. Ingmar Bergman. Svensk Filmindustri, Suécia, 1957. 91 mins.

O rosto [longa-metragem]. Dir. Ingmar Bergman. Svensk Filmindustri, Suécia, 1958. 100 mins.

O olho do diabo [longa-metragem]. Dir. Ingmar Bergman. Svensk Filmindustri, Suécia, 1960. 87 mins.

Através de um espelho [longa-metragem]. Dir. Ingmar Bergman.

Svensk Filmindustri, Suécia, 1961. 89 mins.

O silêncio [longa-metragem]. Dir. Ingmar Bergman. Svensk Filmindustri, Suécia, 1963, 95 mins.

Persona [longa-metragem]. Dir. Ingmar Bergman. Svensk Filmindustri, Suécia. 1966, 85 mins.

$O$ rito [longa-metragem]. Dir. Ingmar Bergman. Cinematograph AB, Suécia, 1969. 72 mins. 
Fanny $e$ Alexander [longa-metragem]. Dir. Ingmar Bergman. Cinematograph AB/ Svenska Filminstitutet et al., Suécia, 1982. 188 mins.

Depois do ensaio [longa-metragem]. Dir. Ingmar Bergman. Cinematograph AB/ Personafilm GmbH, Suécia,1984. 75 mins.

Recebido em 2015-10-09. Aceite para publicação em 2016-03-01. 